\title{
ASSESSMENT OF TUNNELING INDUCED DAMAGE ON HISTORICAL CONSTRUCTIONS THROUGH A FULLY COUPLED STRUCTURAL AND GEOTECHNICAL APPROACH
}

\author{
ANGELO AMOROSI ${ }^{*}$, MARIALUIGIA SANGIRARDI ${ }^{2}$, GIANMARCO de FELICE $^{2}$ \\ AND SEBASTIANO RAMPELLO ${ }^{1}$ \\ ${ }^{1}$ Department of Structural and Geotechnical Engineering, Sapienza University of Rome \\ Via Eudossiana 18, 00184, Rome, Italy. \\ e-mail: \{angelo.amorosi,sebastiano.rampello\}@uniroma1.it, https://web.uniroma1.it/disg/ \\ (*corresponding author) \\ ${ }^{2}$ Department of Engineering, Roma Tre University \\ Via Vito Volterra 62, 00146, Rome, Italy. \\ e-mail: \{marialuigia.sangirardi,defelice\}@uniroma3.it, https://www.romatrestrutture.eu/
}

Keywords: Tunnel construction, Masonry, Soil-Structure interaction, Nonlinearity

\begin{abstract}
The development of urban mobility implies the construction of tunnels, often interacting with valuable historical structures. It is thus necessary to develop rational and reliable procedures to estimate the potential excavation-induced damage, dealing with complex soil-structure interaction problems. Classical approaches are often characterised by relatively simple schematisations for either one or both components of the problem, as, for example, springs for the soil or equivalent plates for the structure. Such simplified assumptions prove to be appropriate for simple soil-foundation cases, while show several limitations when tackling more complex problems, as those involving the excavation in the vicinity or beneath historical masonry structure. In such cases, the need for reliable prediction of the potential damage on surface structures induced by construction activities justifies the adoption of advanced numerical approaches. These need to be based on realistic constitutive assumptions for both soils and masonry elements and require the definition of the three-dimensional geometry as well as an accurate modelling schematisation of the excavation process. In this paper a $3 D$ Finite Element approach is proposed to model in detail the excavation of twin tunnels, accounting for the strongly non-linear soil behaviour, interacting with monumental masonry structures, carefully modelling their geometry and non-linear anisotropic mechanical behaviour. The work focuses on a specific case-study related to the ongoing construction of the line $C$ of Rome underground.
\end{abstract}

\section{INTRODUCTION}

Urban densification requires the construction of new infrastructures to support mobility. This often implies the excavation of underground tunnels, which can interact with valuable surface buildings causing damage. The assessment of tunnelling-induced damage has traditionally been tackled by the decoupled approach, i.e. applying to the structure the displacement profiles 
previously evaluated by free-field analyses of the excavation, thus neglecting all the tunnelsoil-structure interaction effects. Nowadays, more advanced coupled numerical approaches can be used resulting in more accurate description of existing structures, via equivalent embedded solids (e.g. [1]) or through an accurate simulation of their geometry (e.g. [2]), which seem to be particularly necessary when dealing with sensitive historical masonry structures.

This can only be attained with advanced three-dimensional (3D) numerical models, in which a realistic simulation of the excavation process can be performed. Moreover, the non-linearity of soil behaviour, the damaging processes involving masonry structures and the consequent evolution of the interaction process can be effectively taken into account. In the following, the 3D numerical coupled approach adopted to study an interaction problem for the Metro $\mathrm{C}$ line in Rome is described. The case study is first presented and the numerical model with the constitutive assumptions of both the soil and masonry are then described. Finally, the results of free-field and interaction three-dimensional analyses are presented.

\section{CASE STUDY}

The line C of Rome underground runs, with a total length of $25.6 \mathrm{~km}$, from South-East to North-West of the city. It is characterised by twin tunnels with a single track, excavated using an earth pressure balance (EPB) tunnel boring machine (TBM) with an outer diameter $D=6.7$ $\mathrm{m}$, at depths of 27 to $55 \mathrm{~m}$ and average distances of 20 to $40 \mathrm{~m}$. Contract T3 of the line, which

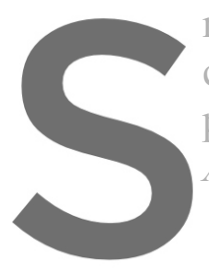
runs for $3.6 \mathrm{~km}$ betwee currently under construct passes the ancient Aradam/Ipponio station
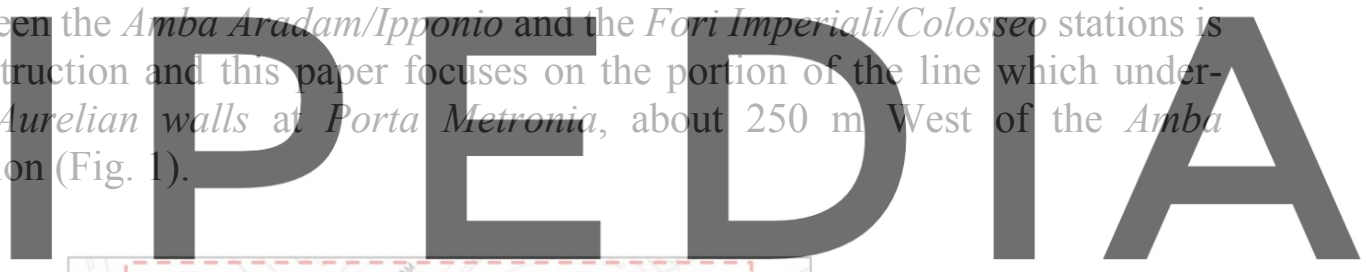

Register for free at https//www.scipedia.com to download the version without the watermark

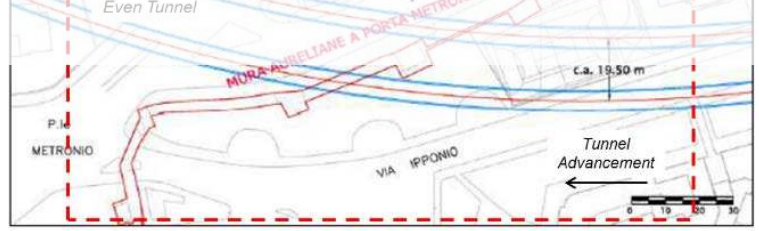

Figure 1: Plan view of the model (dashed red line marked the analysed portion).

The odd and even tunnels under-cross the Aurelian Walls at depths of $27.5 \mathrm{~m}$ and $28 \mathrm{~m}$, respectively, with a cover to tunnel diameter ratio $C / D=3.60$ and 3.68: both tunnels form an angle of about $30^{\circ}$ with the wall axis, in plan, and deepen below the wall with a slope of about $3 \%$.

The ground conditions at the site are shown in Fig. 2, which refers to the longitudinal section through the odd tunnel. It is characterised by an upper layer of coarse-grained made ground (MG), about $13 \mathrm{~m}$ thick, overlying the alluvial deposits of Pleistocene age. These consist of a layer of sandy silt and silty sand (LSO), underlain by a layer of sandy gravel (SG). A thick 
deposit of stiff and overconsolidated clay from the Pliocene is found underneath the gravel, at about $3 \mathrm{~m}$ below the sea level.

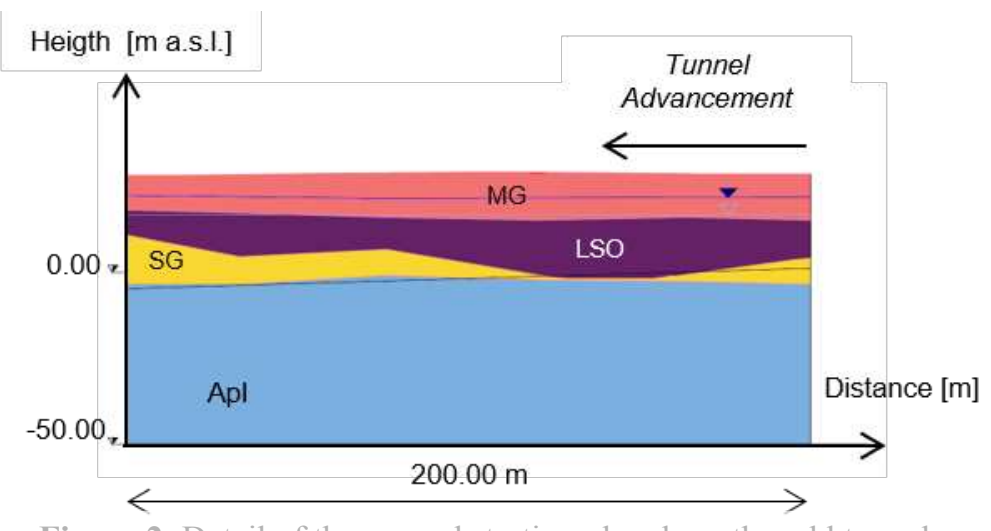

Figure 2: Detail of the ground stratigraphy along the odd tunnel.

The Aurelian Walls are large defensive walls built by Emperor Aurelian between 270 and 275 A.C. Most of their length $(12.5 \mathrm{~km}$ over $19 \mathrm{~km})$ has survived past centuries in a fairly good preservation state. Porta Metronia is in the Southeastern part of the town wall. Both in-situ and laboratory tests have been performed to detect masonry characteristics and identify its mechanical properties.

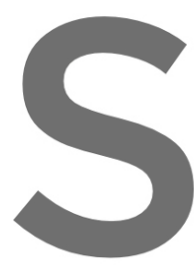

The geometry of the stiffness and strength pr p tests on mortar and core a complex geometry that first branch $(b 6-b 7)$ is made by a single leaf str
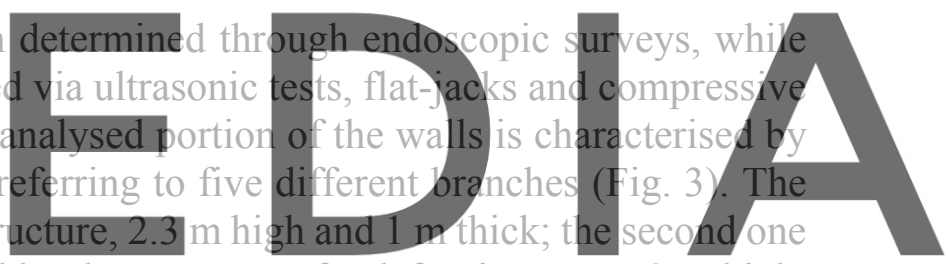
(b7-b8), similar to the former, is characterised by the presence of a defensive tower $9 \mathrm{~m}$ high,

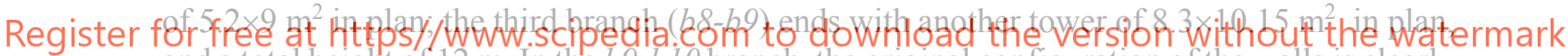
and a total height of $12 \mathrm{~m}$. In the b9-b10 branch, the original configuration of the walls is clearly visible, with the two facings connected by a series of arches and barrel vaults. The last section (b10-b11) is characterised by the presence of another tower, followed by a double facing portion of the walls very similar to the previous one (Fig 4 b,c).
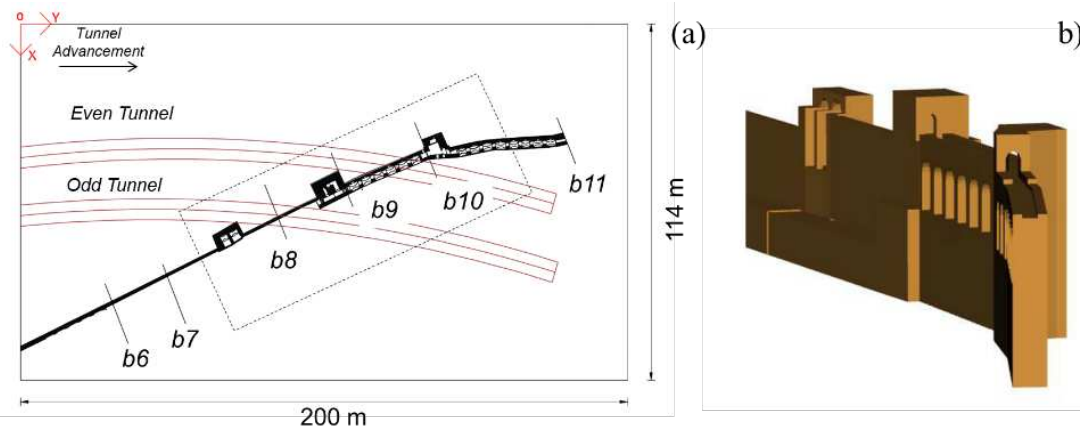

Figure 3: Plan identification of Walls sections (a) and 3D view of the structural model (dashed box) (b). 
The considered portion of the walls features the typical roman building technique of the opus latericium (Fig. 4a) consisting of a brick-faced concrete core. The two external masonry leaves of the ancient wall have been schematised as a periodic assembly of bricks interacting through mortar joints.

\section{NUMERICAL MODELLING}

The numerical study was performed using the FE code Plaxis 3D [3]. The model was set up to simulate the twin tunnel excavation under free-field conditions and in presence of the Aurelian Walls.

Vertical boundaries of the model were restrained horizontally, normal to the mesh sides, while the base of the mesh was restrained both horizontally and vertically. The analysis was performed as follows: model initialisation; walls construction (only in the coupled analysis); odd tunnel excavation; even tunnel excavation. The excavation of each tunnel is simulated by a step-by-step procedure consisting of a series of progressive advancements, each having the length of one concrete lining ring according to the procedure reported in $[4,5]$.

All the analyses here discussed were carried out before the actual construction of the infrastructure, imposing the design volume loss $V_{\mathrm{L}}=0.5 \%$ and neglecting the activation of possible mitigation measures to prevent tunnelling-induced damage, such as compensation grouting, included in the final design. It is worth remarking that the volume loss is defined as

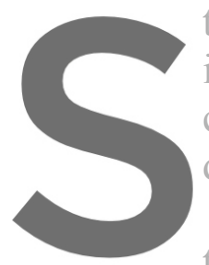
the ratio of the volume

it is a key scalar indica construction one) effects distribution. The value The soil profile was the interaction model. Tite
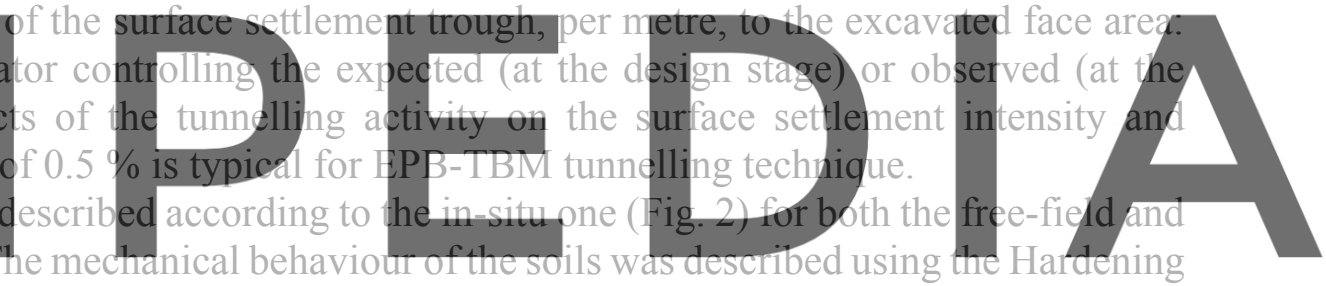

Soil model with small-strain stiffness (HSsmall, [6]) for the sandy silt and the Hardening soil

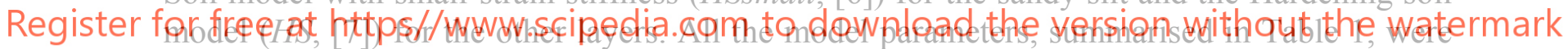

calibrated based on the extensive geotechnical investigation, consisting of several in situ and laboratory tests, discussed in detail in [8].

The structure has been accurately reproduced, though some necessary modelling simplifications have been introduced. The complex geometry of the walls has been replicated between sections $b 6$ and $b 11$, but single leaf masonry has been assumed for the wall portion between section $b 6$ and the left boundary of the model. Despite the presence of some discontinuities between the towers and the walls, in this model they have been considered as perfectly connected. The depth of the foundations has been considered constant according to the information available from previous surveys on the structure, and the ground surface on both sides of the wall is here assumed having the same elevation. 

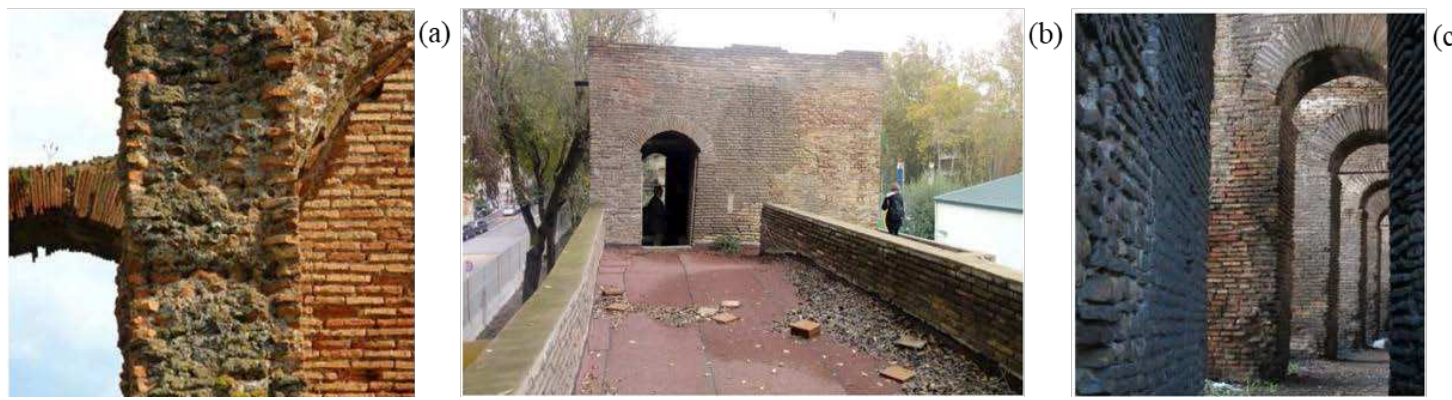

Figure 4: Detail of the opus latericium (a), portion of the walls close one of the towers in the $b 8-b 9$ branch (a) and transversal arches in the $b 9-b 10$ branch (b).

The constitutive model adopted for masonry is a three-dimensional anisotropic elasticperfectly plastic one (Jointed Masonry Model, JMM [9]), in which block aspect ratio and staggering joints effects are considered.

Table 1: Soil model parameters ( $\gamma$ : unit weight; $c^{\prime}$ and $\phi^{\prime}$ : effetive cohesion and friction angle; $\mathrm{G}_{0}{ }^{\text {ref: }}$ : reference shear modulus at very small strains; $\gamma_{0.7}$ : shear strain at which the secant shear stiffness equals $0.7 \mathrm{G}_{0}$; $v^{\prime}$ : effective Poisson's ratio; E' ur ref: reference unloading/reloading stiffness at engineering strains; E' ${ }_{50}{ }^{\text {ref. }}$ reference secant stiffness in standard drained trisxial tests; $\mathrm{E}^{\prime}{ }_{\text {oed }}{ }^{\text {ref. }}$. reference tangent stiffness for primary oedometer loading; m: power of the stress-level dependency of stiffness).

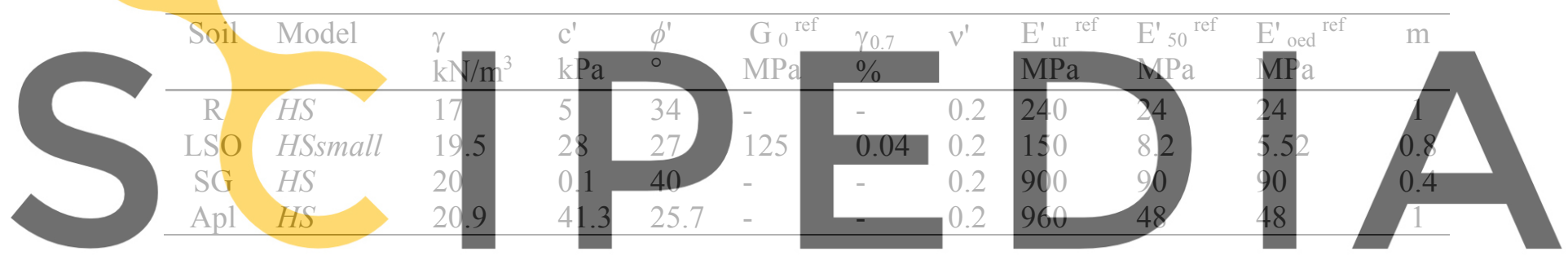

Macroscopic elastic properties are derived in the framework of homogenisation theory of

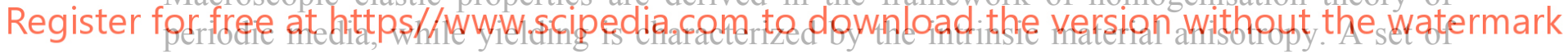

(maximum) three sliding directions, on which failure is meant to occur, is defined in the $x y z$ space and described by means of dip and strike angies, representing, for each piane, the positive rotation along the $x$-axis and the negative rotation along the $z$-axis, respectively [10]. In the analyses only two planes (head and bed joints) are activated. Yield functions are defined, for each orientation, in terms of local stress components according to Coulomb's and tensile criterion as follows:

$$
\begin{gathered}
f_{i}^{c}=\left|\tau_{i}\right|+\sigma_{n, i} \tan \phi_{i}-c_{i} \\
f_{i}^{t}=\sigma_{n, i}-\sigma_{t, i}
\end{gathered}
$$

where $i=1,2,3$ stands for the plane, $\sigma_{n, i}$ and $\tau_{i}$ are the normal and the shear stress along each orientation, $\phi_{i}$ is the friction angle, $c_{i}$ is the cohesion and $\sigma_{t, i}$ is the tensile strength along the joints. The interlocking effect is accounted for by modifying the strength parameters on the head-joints plane, stemming from equilibrium conditions and considering the aspect ratio of the blocks through the parameter $\beta$, which depends on the friction angle of the bed joints: 


$$
\beta=\tan \phi_{2} \frac{b}{2 a}
$$

Tensile strength and cohesion on the head joints are hence calculated according to the following expressions:

$$
\begin{gathered}
\sigma_{t, 1}=\sigma_{t 0,1}-\beta \sigma_{n, 2}+c_{0,2} \frac{\beta}{\tan \phi_{2}} \\
c_{1}=c_{0,1}-\left(\beta \sigma_{n, 2}-c_{0,2} \frac{\beta}{\tan \phi_{2}}\right) \tan \phi_{1}
\end{gathered}
$$

The constitutive parameters adopted in the analysis are summarised in Table 2. Bed joints plane is characterised by both dip and strike angle equal to $0^{\circ}$, while head joints plane angles $\alpha_{1}$ and $\alpha_{2}$ need to be defined in every branch according to its relative rotation around the $z$ axis.

Table 2: Jointed Masonry Model (JMM) constitutive parameters.

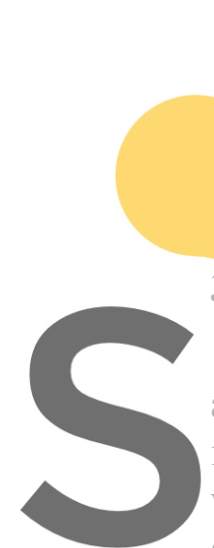

\begin{tabular}{ccccccc}
\hline $\mathrm{G}$ & $v$ & $\gamma$ & $\phi_{\mathrm{i}}$ & $\mathrm{c}_{0, \mathrm{i}}$ & $\sigma_{\mathrm{t} 0, \mathrm{i}}$ & $\beta$ \\
$\mathrm{MPa}$ & - & $\mathrm{kN} / \mathrm{m}^{3}$ & ${ }^{\circ}$ & $\mathrm{kPa}$ & $\mathrm{kPa}$ & - \\
\hline 1000 & 0.15 & 10 & 30 & 50 & 25 & 1.8 \\
\hline
\end{tabular}

\subsection{Free-Field conditions}
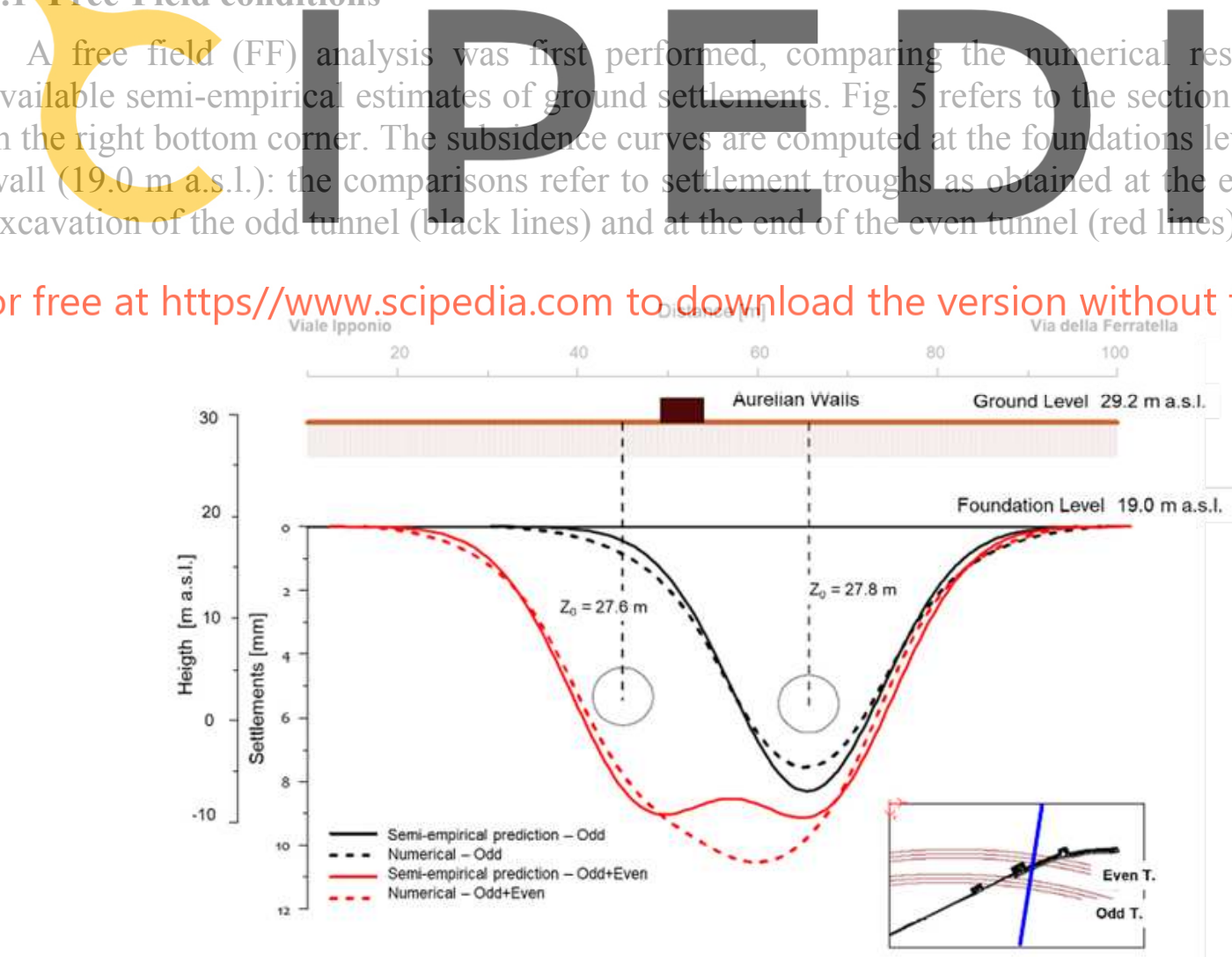

Figure 5: Settlement troughs at the walls foundation level according to semi-empirical predictions and numerical results (free-field conditions). 
For the first odd tunnel, the numerical and semi-empirical predictions are in a reasonable agreement; instead, they exhibit different patterns when referring to the excavation of both tunnels, as a consequence of the plasticity-related non-linear interaction effects, realistically accounted for by the numerical model while disregarded in the empirical approach.

\subsection{Interaction with the Aurelian Walls}

Fig. 6 compares the results of the above free field analysis with those obtained by the coupled analysis, in which the 3D tunnel excavations are simulated considering the presence of the Aurelian Walls.

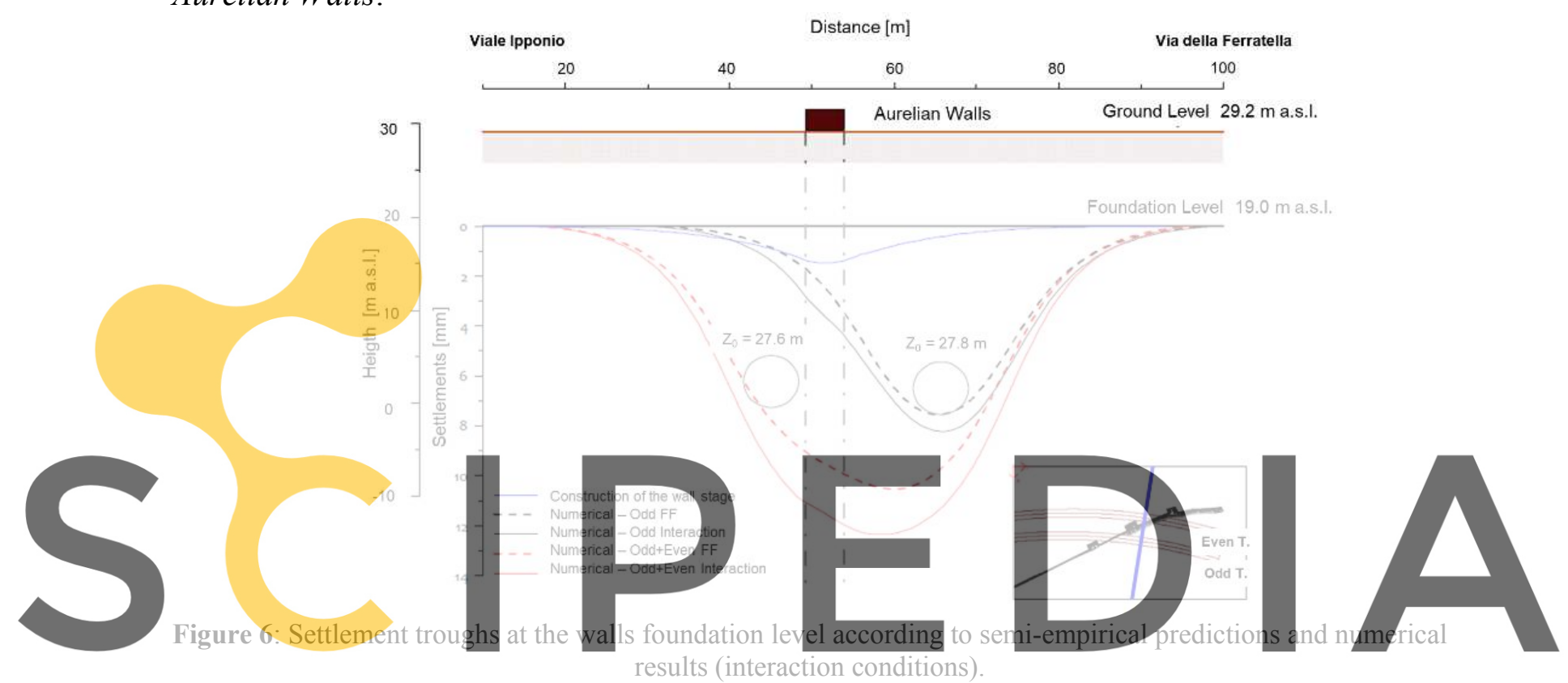

Register for free at https//www.scipedia.com to download the version without the watermark
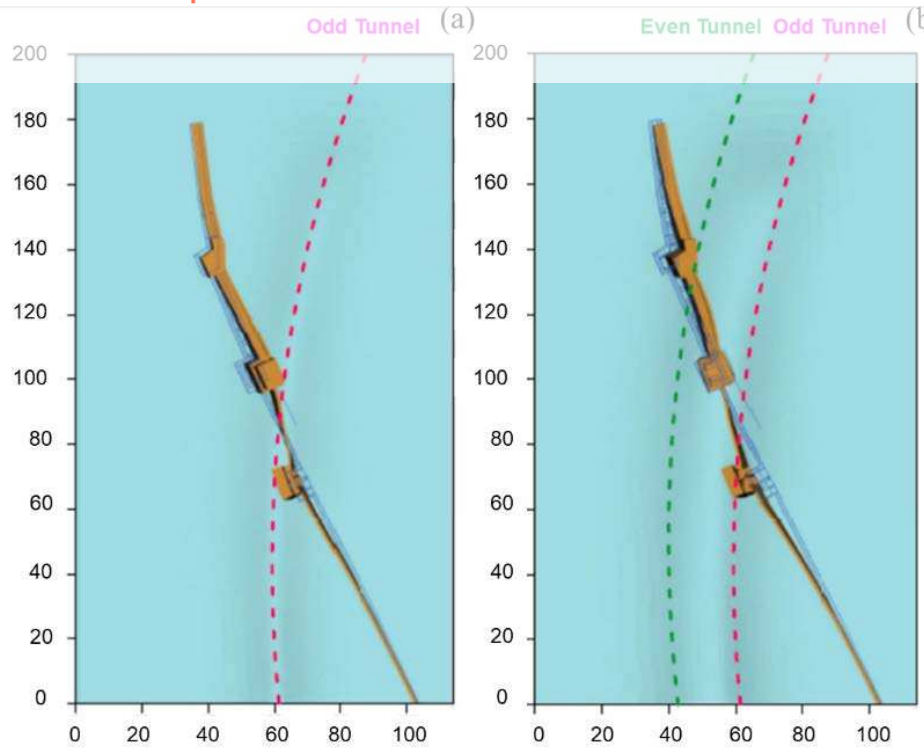

Figure 7: Magnified deformed mesh at the end of the excavation of the odd tunnel (a) and of the even tunnel (b). 


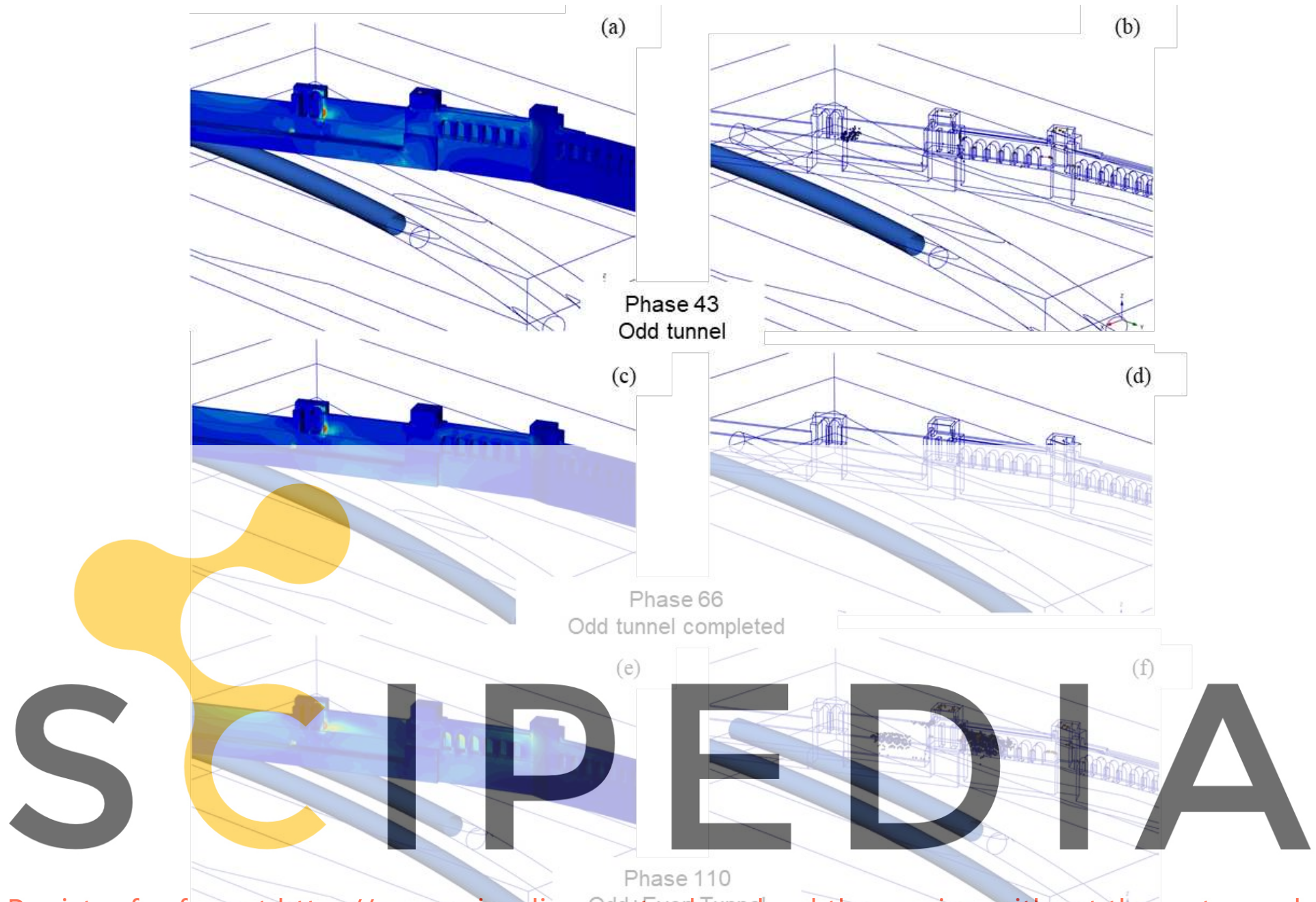

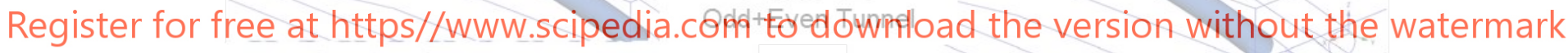

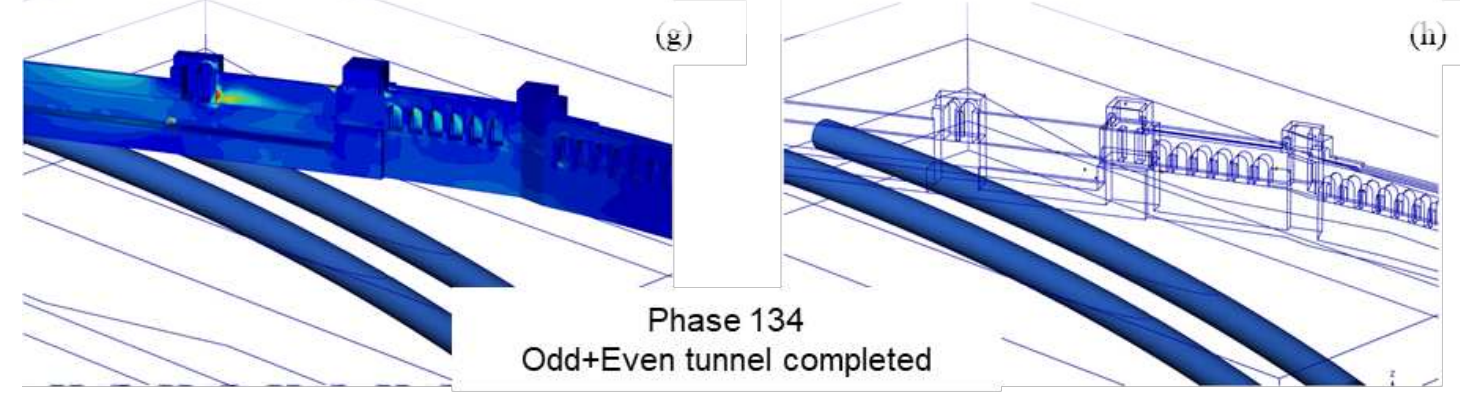

Figure 8: Tensile strain (a, c, e, g) and plastic points distribution (b, d, f, h) at different stages of the excavations.

It reports the subsidence profile at the same location considered in the FF case, at the end of each of the stages defined in the previous paragraph.

The interaction with the surface structure leads to larger settlements, while substantially preserving the shape of the settlement troughs, apart from their portions located directly below the walls, where the stiffness of these latter results in a lower inflection of the curves. 
To better understand the kinematic developing during the entire process, a top view of the magnified deformed mesh of the walls is reported in Fig. 7. It shows the trace of the undeformed walls and the deformed one at the end of the excavation of the first tunnel (a) and of both tunnels (b), highlighting the out-of-plane rotation induced by tunnelling. Torsional effects are evident and contribute to the development of the tensile strain patterns during the excavation process, which are reported in Fig. 8. These are traditionally adopted to interpret damage intensity and distribution $[11,12]$.

In this case, tensile strain patterns (results refer to four different stages of the analysis) are reported together with the plastic points distribution (i.e. points in which the tensile or shear failure has been reached). The observation of these indicators suggests that the excavation of the even tunnel (Phase 110) is responsible for most of the damage detected on the structure and that these effects are mainly located at the wall-tower connection. It is worth noting that the amount of predicted damage is very low, confirming the correctness of the design solutions adopted for this important infrastructure.

\section{CONCLUSIONS}

In this paper, a complex soil-structure interaction case involving a portion of the Aurelian Walls affected by the excavation of the T3 contract of the line $\mathrm{C}$ of Rome underground has been studied.

The analyses have b presence of the walls, mechanical behaviou calibration of the mecha previously performed on both materials. The
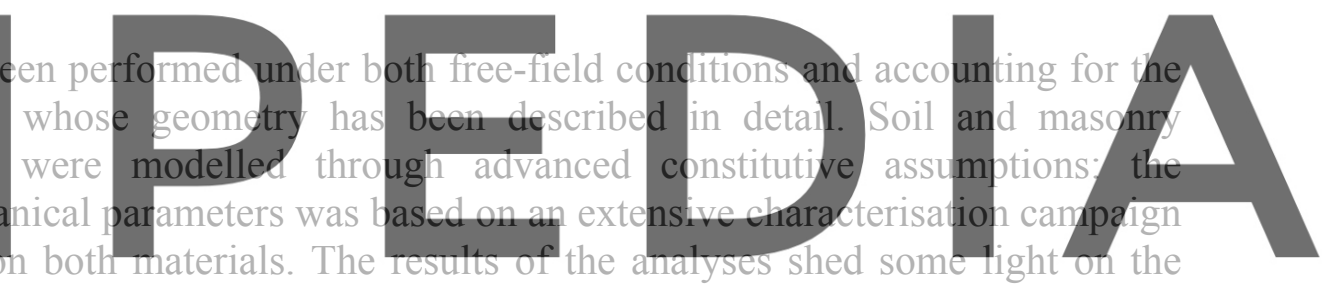

evolution of the low damaging process occurring within the masonry structure, thanks to both

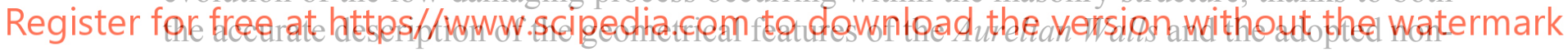

linear masonry constitutive model. In particular, not all the excavation phases seem to equally affect the structure and, possibly more interestingly, the greater damaging condition does not necessarily correspond to the final stage of tunnel excavation, when both tunnels are completed. Indeed, modelling the staged construction and the real three-dimensional conditions permitted to detect torsional effects that would be otherwise lost in any conventional 2D approach.

\section{REFERENCES}

[1] Rampello S., Callisto L., Viggiani G., Soccodato F.M. Evaluating the effects of tunnelling on historical buildings: the example of a new subway in Rome. Geomechanics and tunnelling (2012) 5(3): 275-299.

[2] Amorosi, A., Boldini, D., de Felice, G., Malena, M. and Sebastianelli, M. Tunnellinginduced deformation and damage on historical masonry structures. Géotechnique (2014) 64(2):118-130.

[3] Brinkgreve, R. B. J., et al. "PLAXIS 2016." PLAXIS bv, the Netherlands (2016).

[4] Fargnoli, V., Gragnano, C.G., Boldini, D. and Amorosi, A. 3D numerical modelling of soil- 
structure interaction during EPB tunnelling. Géotechnique (2015) 65(1):23-37.

[5] Burghignoli A., Callisto L., Rampello S., Soccodato F.M., Viggiani G.M.B. The crossing of the historical centre of Rome by the new underground Line C: a study of soil structureinteraction for historical buildings. In Geotechnics and Heritage: Case Histories, CRC Press, London (2013), pp. 97-136

[6] Benz, T. Small-strain stiffness of soils and its numerical consequences. Ph.D. thesis, Universität Stuttgart (2007).

[7] Schanz, T., Vermeer, P.A. and Bonnier. P. G. The hardening soil model: formulation and verification. Beyond 2000 in computational geotechnics (1999): 281-296.

[8] Rampello S., Fantera L. and Masini L. Efficiency of embedded barriers to mitigate tunnelling effects. Tunnelling and Underground Space Technology (2019) 89:109-124.

[9] Lasciarrea, W.G., Amorosi, A., Boldini, D., de Felice, G. and Malena, M. Jointed Masonry Model: A constitutive law for 3D soil-structure interaction analysis. Engineering Structures (2019) 201.

[10] Sangirardi, M., Malena, M. and de Felice, G. Settlement Induced Crack Pattern Prediction Through the Jointed Masonry Model. In Proceedings of XXIV AIMETA Conference 2019, Springer International Publishing 24 (2020), pp. 1971-1980.

[11] Boscardin, M. D., and Cording, E. J. Building response to excavation-induced settlement. Journal of Geotechnical Engineering (1989) 115(1): 1-21.

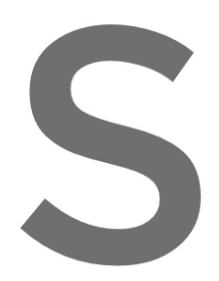

[12] Sangirardi, M., Amorosi, A. and de Felice, G. A couple
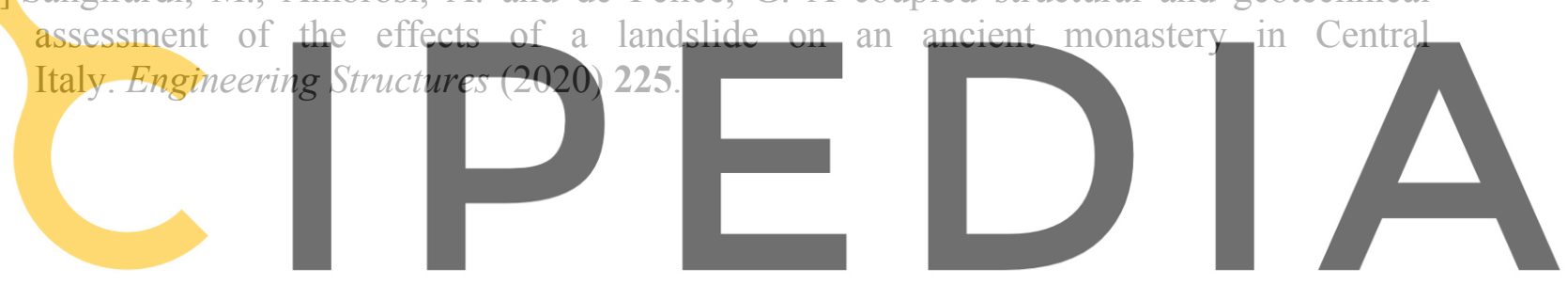

Register for free at https//www.scipedia.com to download the version without the watermark 